\title{
Environmental impact assessment of the proposed residential project "NEST" for Enerrgia Skyi developers in Pune, India
}

\author{
U. S. Kulkarni, F. Sayed \& K. M. Nair \\ Fine Envirotech Engineers, India
}

\begin{abstract}
M/s. Enerrgia Skyi Developers proposes developing a quality residential township "NEST" at Bhugaon in Pune, India by converting the existing land to an evergreen piece of environmentally friendly settlement without displacing any of the present population. The proposed scheme consists of 20 towers of 12 floors with parking and 38 town houses spanning a total plot area of $172,282 \mathrm{sq}$. m. including a green belt of 85,766 sq. m. It will support environmentally viable activities like rainwater harvesting, 35\% energy conservation plans, recycling of waste water and debris, etc. Also, the project proponent proposes developing a green belt to maintain the existing bio-diversity and minimize the air pollution that may arise during the operational phase. Out of the total existing 196 trees, 24 would be transplanted and 3100 more would be planted to enhance the ecosystem of this region. EIA was conducted by Fine Envirotech Engineers on this project, taking into account the important environmental parameters. BES and impact assessments were conducted in the area of $10 \mathrm{~km}$ around the proposed site. Depending on the spatial relationship of various land use along the project road and wind direction, quality monitoring of major parameters were performed at 5 different locations. The average readings of all important parameters like air, water, noise, socio-economic, biodiversity, etc. were found to be within permissible values stipulated by CPCB. Mitigating measures, environmental management plans, disaster management plans, and risk assessments will be adopted and conducted suitably. Thus, based on EIA, this project is environmentally sustainable and with effective EMP and DMP; it would have a major positive impact in the area on the whole.

Keywords: township development, environmental impact assessment, rain water harvest, baseline environment study.
\end{abstract}




\section{Introduction}

This paper discusses the environmentally friendly practices employed by the residential developers and the regulations that are mandatory for construction projects; which together leads to a sustainable development project. For this purpose, such a sustainable residential project of "NEST" at Bhugaon village, Pune have been discussed a prime example. M/s. Enerrgia Skyi Developers proposes to develop a residential development project in Pune, India. The project consists of 20 towers with parking and 12 levels of flats and 38 town houses with 2 levels and parking. The project is planned in such a way that the residents would be provided with all the basic amenities and utilities required to survive self sufficient community with high quality life style. All this would be provided with sustainable development as the first priority. These developers have prior experience in developing successfully such environmentally friendly residential projects. According to the EIA Notification, 2006 issued by MoEF, townships /area development projects covering an area of more than 50 ha and/or a built up area of more than 1,50,000 sq $\mathrm{m}$ are clubbed under Category B and falls under the schedule number $8(\mathrm{~b})$. This would also entail that the project would require prior environmental clearance from SEAC, SEIAA and MoEF. As their environmental consultant, M/s. Fine Envirotech Engineers are responsible for all the formalities and documentations required for the same. FEE has conducted Baseline environmental status of the area, designed EMP, DMP, EMntP, evacuation plans, etc for this project. As part of the application to the MoEF, two standard forms formulated as part of the EIA Notification, 2006 have been filled in - FORM I and FORM IA. These two forms would contain all the information regarding every minute detail of the project in tabular form, making it easy for the environmental committee to review them. As part of the sustainable development plans associated with this project, the developer has now included rainwater harvesting, Sewage treatment plans, Solid waste management plans, storm water management, greenbelt development, etc. Environmental impact assessment of the project has been performed, mitigation measures have been planned, and monitoring plans have been set, sustainable development measures have been formulated; making this residential project an ideal case study for future projects because its development would only have positive impacts and very negligible negative impacts on the residents or the environment.

\section{Need and benefit of the project}

The proposed project will include 20 numbers of towers with 12 floors and parking, 38 numbers of town houses with 2 floors and parking. The proposed site is an open ground at present. The development of this project at this site is essential to improve the aesthetics of the area while turning it into an evergreen piece of environmentally friendly settlement. It will also lead to employment opportunities temporarily during the construction phase and permanently after the development. This project will be able to provide quality residential accommodation. By following the environmental management plans and 
monitoring schedules, this project will be a prime example of sustainable residential development project.

\section{Sustainable residential development}

All the policies and regulations that govern the different sections of a residential development project aim to aim to provide successful and sustainable residential development especially in urban areas, where there is constantly rising rates of immigration. Accordingly, housing developers, the planning system and the community they serve all should share a common goal to create high quality places with the following characteristics:

$>$ Give more importance to walking, cycling and public transport;

$>$ Provide a quality of life that can be expected in an urban area in relation to the utilities, convenience, amenities and security;

$>$ Conserve energy and other resources and implement measures to prevent or minimize any adverse effects on the environment;

$>$ Provide convenient transport system, accessibility to utilities and social centres;

$>$ Enhance and protect the built and natural heritage.

This project also follows most of these measures as much as possible economically and environmentally (Huseynov [1]). The project will be following measures like using concrete blocks containing at least $20 \%$ fly ash for construction, acoustic enclosures to DG sets for prevention of noise, efficient energy conservation plan, create awareness among the residents about energy conservation and energy star electrical appliances, etc. Every individual involved in this project will be made aware of the long term and short term benefits of these sustainable measures. Every resident would be made aware about the broad benefits as well as personal economic benefits like low utility bills by implementing the measures advocated for sustainable development.

\section{Environmentally friendly practices}

The project proponent will be implementing many environmentally friendly practices as discussed below. The project has also been registered with Indian Green Building Council and is pursuing a gold certification from them.

\subsection{Green belt development}

It has been proposed that about $50 \%$ of the total plot area will be developed into a green belt region with plantation of various trees and plants. At present the site has 196 trees, out of which 24 will have to be transferred to a different part of the plot. Also, 3100 more trees would be planted in this green belt region. This number has been calculated based on the regulation of planting at least 1 tree per 56 sq. $\mathrm{m}$. For this entire green belt development, 350 lakhs have been allocated out of the total project cost and another 35 lakhs have been calculated as 
operation and maintenance cost for the coming years. The species of the new trees have been selected to enhance the native biodiversity and landscaping.

\subsection{Waste management plant}

This practice will have to be addressed separately during the different phases of the project as the content of the wastes generated during construction phase and operational phase would be very different. During the construction phase, the waste would usually contain soil and rubble, which will be reused for leveling and landscaping on-site itself. Any construction spill-over will be minimized and controlled. Throughout the construction phase the wastes will be segregated at the source and recycled or reused or disposed off according to the norms and regulations. During the operational phase the waste generated would mostly be domestic waste and would include paper, glass bottles, plastics, food items, etc. The total solid waste has been calculated to be around $4930 \mathrm{~kg} / \mathrm{day}$. Out of this total waste, $2878 \mathrm{~kg} /$ day would be biodegradable wastes while about $2052 \mathrm{~kg} /$ day would be non-biodegradable wastes. These would be separated at the source. Separate bins would be placed for collection of each type of wastes and disposed off accordingly. Biodegradable waste would be composted at Organic waste convertor plant on-site and the manure thus produced will be used for the green belt development. The sanitary waste water to be generated by the developed project has been calculated to be around $1166 \mathrm{~m} /$ day, which will be treated in sewage treatment plant of a capacity of $1169 \mathrm{~m}$. The treated water from sewage treatment plant will then be used for flushing and gardening purposes within the area. The estimated sludge production per day has been calculated to be around $80 \mathrm{~kg}$. This will be used as manure for gardening. Capital cost of 110 lakhs has been assigned out of the project cost towards the STP plant and an additional 25 lakhs per annum towards the operation and maintenance of the plant. The STP being proposed is Suspended Media Bio-reactor based technology that has many advantages over the conventional technologies like less area requirement, absence of sludge recycler, minimal moving parts and hence less maintenance, etc.

\subsection{Rainwater harvesting}

The entire rooftop area of around $28,484 \mathrm{sq} \mathrm{m}$ will be designed so as to maximize rainwater harvesting and directs the harvest to filters and then to collection sumps. Arrangements will also be made to either pump the harvested water to the tanks made for storage/distribution of reuse water, or for turbidity removal plus disinfection so that it can be used for drinking and cleaning (Basu et al. [2]). The entire landscaping (143,798 sq. m) will be done in such a way that there are specific slopes to the land so that the surface runoffs can get collected into the assigned ponds or tanks for further treatment/distribution. The recharging pits will be provided with grease cum de-silting chambers. 


\subsection{Storm water collection and disposal}

Storm water usually just runs off the areas and flow into the water bodies without any kind of treatment. This can pollute the water bodies like creeks, lakes and rivers and have adverse effects on their chemical as well as biological nature. In this project, all along the roads storm water drains would be provided to collect water during rains. They would be adequately sized to prevent overflooding of the site. Storm water drains will be collected through network of storm drains from gardens, parking areas, paved and unpaved areas, and roadways. Storm water from plot area will be collected in the rainwater harvesting pits provided for this purpose. Plans for storm water collection has been proposed in such way so as to accommodate the entire amount of outflow, that may occur after development, i.e., around $93.74 \mathrm{~m}^{3} / \mathrm{min}$.

\subsection{Energy conservation}

Energy conservation methods have been devised according to the project specific report submitted by a USA based company named dbHMS Inc. According to this study report, the project developer will be implementing measures like use of electronic ballast instead of the conventional ones, use of automatic timer operation for all the lightings provided in the parking areas as well as the landscaping, use of low loss transformers, solar water heating, use of solar based stand alone system for street lighting. These measures would help direct conservation of about 13,560 units of electricity per annum. Other measures that would be implemented to conserve energy indirectly, including optimization of building plan for energy efficiency using computer simulation and modeling, cavity walls, good shading for the windows, use of high efficiency pumps and motors, utilization of wind power, etc.

\section{Traffic analysis and parking}

Traffic impact assessment report has been prepared for this project for traffic management during both construction as well as operational phases. This report summarizes the present situation of the traffic in this area and around it, the possible effects on the traffic due to the development of this project, traffic management measures to be implemented to prevent any additional pressure on the existing flow of traffic. The project site has two approach roads. A $60 \mathrm{~m}$ wide main road is only $100 \mathrm{~m}$ away from the site. A road of $18 \mathrm{~m}$ wide connects this main road with the project site.

According to the number of houses planned for this project and an estimate of the number of residents, required parking number for two wheelers, four wheelers and bicycle have been calculated. In the proposed plan, 10-15\% more area has been provided for parking, compared to the required area. Visitors parking has been calculated and allotted separately. These parking areas would be able to accommodate any increases in the vehicle numbers and hence will not pressurize the areas nearby for parking. 


\section{Environmental impact assessment}

EIA is essential to protect the environment (including the physical, chemical and biological components of the ecology) from possible adverse effects a proposed project might have during any of its phases. MoEF has set mandatory regulations through EIA Notification in 2006 the necessary analysis to be performed on different categories of projects. The environmental clearance is granted to the projects only after ensuring that the project would not have any negative impacts and also it employs as many environmentally friendly practices as possible economically. Prior EIA helps to gain not just environmental benefits but also a lot of economic benefits to everyone involved with the project.

\subsection{Stages of EIA}

- An exhaustive EIA process is inclusive of the various steps as described below:

- Screening;

- Scoping and consideration of alternatives;

- Baseline environmental status;

- Impact predictions;

- Assessment of alternatives, delineation of mitigation measures and environmental impact assessment;

- Environmental management plan;

- Public hearing and decision making;

- Monitoring and conditions on which the project was given the clearance.

\subsection{Study area}

To decide whether a proposed action is likely to cause significant adverse environmental effects, the concept of EIA is practiced before proceeding to establish baseline environmental status. More importantly it is necessary to establish the boundary limits and framework, where data can be effectively utilized for impact assessment.

\subsection{Baseline environmental status}

After establishing the scope of work for the EIA, the first step is to establish the BES of the area. Understanding the existing conditions of the proposed site is a pre-requisite for proceeding with any EIA. For this project, monitoring was performed on the following parameters for one season, i.e., from March to April of 2011. Apart from the project site, four nearby locations were monitored for every parameters discussed below - Project site, Lavale village, Pirangut village, Bhukum village and Ahire village.

\subsubsection{Land environment}

The project site is located on the west side of Pune city. The proposed site does not have any archeological structures in the vicinity. The surroundings are very 
natural and has shallow bottom. The plot is almost empty with a few green patches on the periphery. The land use has changed through the times; moving from agricultural land to now being abandoned with no human activities. Some greenery that's remaining is being exploited by the nearby villagers and tribal population.

\subsubsection{Socio-economic aspects}

The study area has adequate water supply, good climatic conditions, fair sewage disposal system, etc. The development of this project would not be affecting any of the locals in a negative way. There will be no need for any rehabilitation as there are no human settlements in this area. On the contrary there will be abundant opportunities for employment during the construction phase (both skilled and labor), although temporary and there will be permanent employment opportunities during the operational period of the project. This upcoming residential would enhance the quality of life in and around this area.

\subsubsection{Air quality}

Air monitoring was performed at five locations including the project site for parameters like $\mathrm{SO}_{\mathrm{x}}, \mathrm{NO}_{\mathrm{x}}, \mathrm{PM}_{2.5}, \mathrm{PM}_{10}$, etc. It was found that the $\mathrm{PM}_{10}$ was found to be slightly higher in two location, viz., Bhukum village and Ahire village, but the values were still within the limits set by CPCB. After monitoring for the current air quality within the $10 \mathrm{~km}$ radius around the project site, it was observed that there will be no adverse effect due to the project on any of these areas.

\subsubsection{Noise quality}

$\mathrm{CPCB}$ has set standard values for noise levels that are permissible at day time or night time. These standards are different for different areas - separate limits for industrial, residential, government offices, etc. After monitoring the noise levels every hour for $24 \mathrm{hrs}$ at the five locations, it was found that no increase in noise levels is envisaged at the proposed site or around it. Being a residential project it is equally important to ensure that the new project will also not face any kind of disturbances from the surrounding areas. All the four locations around the proposed site also had noise levels well below the permissible limits.

\subsubsection{Water quality}

Water is one of the prime requirements at the site to maintain the natural surroundings and meet the various requirements of the different residential and floating communities at the site. The source of water in the region is primarily from the monsoons, which is abundant in the region as runoff water. Water bodies serve as a perennial source of water supply in the area to meet the prevailing needs of the various living communities, including plants and human population. The recycling of water within the project area would suffice the water demand. The nearby water body, Ram Nala is adjacent to the project site but the water quality was found to be neither fit for domestic purpose nor for construction purpose. Even the sewage generated from the project wouldn't be 
released into this water body before being completely treated according to the municipal solid waste management rules. Runoff at the proposed site would be collected through storm water drainage systems and treated before allowing it to enter any water body. Thus, it can be inferred that the project would not have any adverse impacts on the surface or ground water around the proposed site.

\subsubsection{Ecology and biodiversity}

It is essential to understand and predict the possible impacts of the project on the flora and fauna of the area as it is inevitable that the increased human interactions in the area to have some impacts on the ecology of the area. There are very few scattered local trees like Neem, Pangara, Babhul, Bor, etc. Because of absence of a rich habitat, very low variety of fauna can be observed in this region.

\subsection{Impact assessment and mitigation measures}

Once the baseline has been established and the project plans have been designed, the next step is to put these two reports together and assess the impacts on the parameters of the BES due to the implementation of the project. For this purpose, the project is considered in two phases - construction and operational phases.

\subsubsection{Construction phase}

The impacts predicted during the construction phase are as follows:

$>$ Negligible impact on land use;

$>$ Drastic but positive impact on the geology and topography;

$>$ Suspended particulate matter released from construction activities;

$>$ Increased vehicular movements affecting air and traffic temporarily;

$>$ Temporary increase in noise levels due to construction activities or equipment.

Mitigation measures that will be implemented during the construction phase include:

$>$ Segregation and sorting of waste at the source;

$>$ Reuse of excess soil and rubbles excavated during pre-construction phase;

> Controlling the spillover on land during construction activities;

$>$ Covering vehicles carrying raw materials or waste from the site;

$>$ Covering the temporary storage facilities;

$>$ Sprinkling of water to reduce dust emissions;

$>$ Proper acoustic enclosures for noise producing machines or activities;

$>$ Pre-cast materials for construction;

$>$ Any runoffs will be arrested on-site through the storm water drainage system and treated before releasing into any water body;

$>$ Preserve all the flora and fauna during the construction phase;

$>$ Any unpredicted loss to flora or fauna will be compensated during the operational phase adhering to the related norms. 


\subsubsection{Operational phase}

Impacts on various parameters during the operational phase are as follows:

$>$ Commercialization of the area;

$>$ Increased employment opportunities;

$>$ Improved aesthetic look of the area;

$>$ Increased traffic.

Mitigation measured designed to overcome any predicted adverse impacts on the environment are as follows:

$>$ Improved traffic management and allotment of more than enough parking spaces;

$>$ Solid waste management plant would be constructed and utilized to dispose off, the solid waste generated;

$>$ Waste water treatment plant would also be operated to treat every kind of waste water produced on site, some would be reused and others would be let into the drainage system of the municipality, only after treatment;

$>$ Segregation of waste materials at the source.

\subsection{Environmental management plan}

Assessment of the impacts and formulating the mitigation measures to be implemented to avoid the negative impacts would not help ensure the actual implementation. For this purpose, every project should have an EMP as part of its EIA. It is the key to ensure a safe and clean environment. EMP helps to tie up the BES, project plan, its impacts, mitigation measures and also future monitoring and decision makings. During construction phase, EMP mainly takes care of identification of implementing authorities, implementation of recommended mitigation measures, site management plans, maintenance of environmental quality, site security, etc. During operational phase, on the other hand, EMP involves not just mitigation measures but also other activities like rain water harvesting, STP, waste water treatment, energy and water conservation, green belt maintenance, etc. An EMP cell is also established and skilled environmentalists recruited to take care of these issues. Budgets are calculated and added on to the capital cost of the project and an annual sum kept aside for the EMP during operational phase. As part of the EMP, monitoring plans are established for every parameter. Standard daily/weekly/monthly charts have been designed by MoEF which will help maintain the records for these parameters.

\subsection{Risk analysis and disaster management plan}

Emergencies may occur due to various reasons, either manmade or natural. The reasons may be unpredictable like flood, fire, malfunctioning of equipments, earthquake, etc. The scale of these emergencies and their after effects increase with the size of the project. Hence, this large scale project requires a disaster management plan to prevent or minimize the loss or damage of life and property. 
It would help to identify the possible disasters and set plans and responsibilities in such situations. Lack of a prior plan is the main reason for increased avoidable losses during such emergencies. For the project, DMP has been designed for both natural as well as manmade disasters. Emergency equipments' list has been prepared and it would be ensured that these equipments are always available and easily accessible for such emergencies. A hierarchy of individuals responsible for different duties has been designed. After discussing with the architect of the project, evacuation plan has been designed and necessary changes have been accommodated in the project plan.

\section{Conclusion}

The construction projects are governed and regulated by different laws set for various components of the project like water, high-rise, energy, etc. But, there is one regulation issued by MoEF, the EIA of 2006 and the amendments later, that has tied up all these separate components and brought to one stage where every aspect of the construction project is regulated and monitored. Under this act, the residential project must meet the standard criteria set by the Ministry and not only make sure that it does not have any adverse effects on the area, but also should assure the ministry that it will implement sustainable development practices. Every individual involved in the project is now aware of the environmental as well as economic benefits of these processes. Even consumers now prefer such environmentally friendly residential areas as it saves them a lot of money on their utility bills. These projects also are setting examples to the upcoming projects. Government is constantly encouraging such projects by providing incentives through tax remittance, etc.

The main goal of this paper is to set a stage to understand the process of Environmental assessment of residential development projects in India and its benefits. It is necessary for every project proponent to recognize the process of EIA as a systematic methodology that would help the planners to evolve their project towards sustainable development and better economic benefits by choosing the better alternatives (UNEP [3]). Also, completing the EIA even before the pre-construction phase will save a lot of financial losses during the implementation of the project because through EIA, every aspect of the project is revised thoroughly from both environmentalists' and economists' perspectives.

\section{Abbreviations}

MoEF - Ministry of Environment and Forest

EMP - Environmental Management Plan

EMntP - Environmental Monitoring Plan

EIA - Environment Impact Assessment

DMP - Disaster management plan

$\mathrm{PM}$ - particulate matter

CPCB - Central Pollution Control Board

SEAC - State Environmental Appraisal Committee 
SEIAA - State Environmental Impact Assessment Authority

FEE - M/s. Fine Envirotech Engineers

STP - Sewage Treatment Plant

$\mathrm{NO}$ - oxides of nitrogen

$\mathrm{SO}-$ oxides of sulphur

BES - Baseline Environmental Status

\section{References}

[1] Huseynov, E, Planning for a sustainable development of Azerbaijan Republic cities // International Academiya of East Country Architecture, Azerbaijan National Scientific Akademiya, Chapter 5, Architecture, Baku, pp. 99-109, 2010

[2] Basu, S et al., EIA and management for medical college and hospital project of Sri Lakshmiammal Education trust at Agram, Pondicherry, p. 74

[3] UNEP (United Nations Environmental Programme), Global Environment Outlook 3, Earthscan Publications: London, 2002 